Archive for

Organic Chemistry

Arkivoc 2020, part vi, 60-65

\title{
Synthesis of novel dicyclohexeno-crown ethers with strategically incorporated double bonds for further functionalization
}

\author{
Carim van Beek, ${ }^{a}$ Vincent J. Catalano, ${ }^{b}$ and Vyacheslav V. Samoshin*a
}

aUniversity of the Pacific, Department of Chemistry, 3601 Pacific Avenue, Stockton 95211 CA, United States

${ }^{b}$ University of Nevada Reno, 1664 North Virginia Street, Reno 89557 NV, United States

Email: vsamoshin@pacific.edu

Received 02-13-2020

Accepted 03-06-2020

Published on line 03-29-2020

\section{Abstract}

The number of applications found for crown ether-based materials continues to expand. Many of these applications feature dicyclohexano-18-crown-6 (DC18C6). The number of its derivatives, however, is very limited. To provide a suitable starting structure for the preparation of diverse functionalized DC18C6, the trans-syn-trans and trans-anti-trans isomers of dicyclohexeno-18-crown-6 have been synthesized for the first time through a convenient three-step synthetic procedure, yielding both isomers simultaneously. An efficient chromatographic separation resulted in the isolation of the pure isomers, and single crystal X-ray crystallography determined the solid-state structure of these crown ethers.
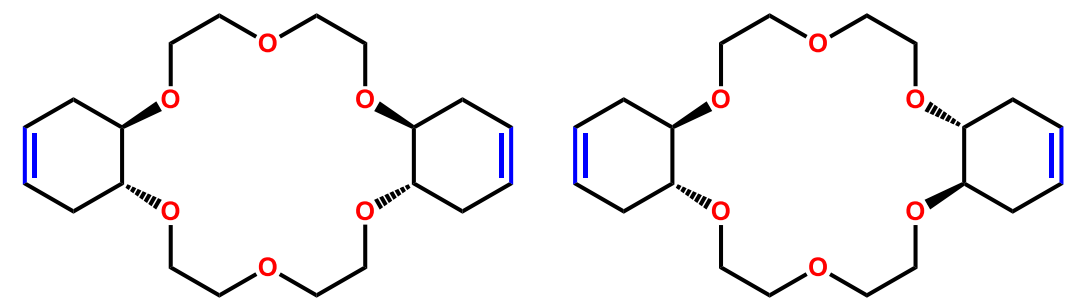

Keywords: Crown ether, dicyclohexeno-18-crown-6, dicyclohexano-18-crown-6, crown ether functionalization 


\section{Introduction}

Ever since their first discovery by Pedersen, ${ }^{1}$ crown ethers have seen a tremendous increase in their standalone applications, ${ }^{2-5}$ as well as their utility as fundamental building blocks comprising higher order structures in the shape of cryptands and (pseudo)rotaxanes. ${ }^{6,7}$ Their unique suitability in host-guest chemistry has sparked the emergence of supramolecular chemistry and molecular machinery. ${ }^{2,4,5,8}$ Additionally, crown ether-based compounds are used for the selective binding of ions, in (phase-transfer) catalysis, membrane transport, and as antitumor agents, either in solution or attached to a solid support. ${ }^{3,9-11}$ Evidently, the range of purposes found for crown ether-based materials is both incredibly broad, and still expanding. Many applications feature dibenzo- (DB18C6) and dicyclohexano-18-crown-6 (DC18C6), ${ }^{1,3,9-11}$ and both their synthesis and physical properties are well described. ${ }^{1,12-16}$ Between these two similar structures, DB18C6 can be further functionalized through incorporation of additional substituents onto the catechol moiety. DC18C6, however, contains a relatively inert cyclohexane ring that severely limits any potential for subsequent functionalization. To this extent, we sought to develop a novel type of dicyclohexene-based crown ether that allows for additional modification of the 6-membered ring, opening up new possibilities for use in a wide range of applications. We envisioned the strategic incorporation of $\pi$-bonds that could further be modified in a variety of ways dependent on the final purpose of the target molecule. The well-defined conformational behavior of cyclohexane-based compounds makes these molecules ideal scaffolds for applications in supramolecular chemistry, ${ }^{4,5}$ where precise control over the shape of the structure is highly desirable. Our goal was to design a quick and convenient synthesis, without the use of any protecting-group strategies, to obtain two of the five possible isomers of dicyclohexeno-18-crown-6 (DCE18C6) (Figure 1) containing a single separation of isomers in the final step. To the best of our knowledge, the synthesis of this novel type of crown ether has not been reported before.
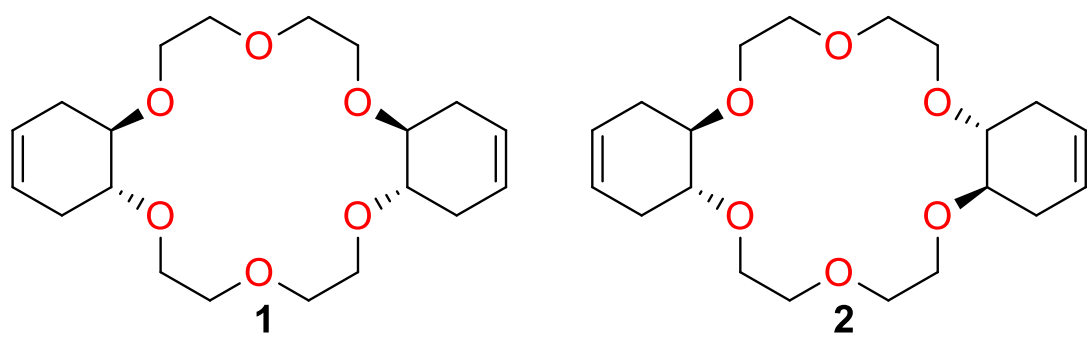

Figure 1. Trans-syn-trans (1) and trans-anti-trans (2) isomers of dicyclohexene-18-crown-6.

\section{Results and Discussion}

The synthesis of crown ethers $\mathbf{1}$ and $\mathbf{2}$ is based on a general strategy, as previously published for the synthesis of DC18C6, ${ }^{15}$ shown in Scheme 1 . Starting from the commercially available 1,4-cyclohexadiene $\mathbf{3}$, epoxide 4 was obtained through reaction with meta-chloroperoxybenzoic acid (mCPBA). In a first attempt, significant quantities of bis-epoxide 4a (cis/trans mixture) were formed in addition to the desired product. The epoxidation of $\mathbf{4}$ to $\mathbf{4 a}$ appears minimally hampered by increased steric hindrance in comparison to the diene 3. To this extent, we conducted an optimization experiment by varying both temperature and the equivalents of $m C P B A$ used. We monitored the ratios between the products formed using gas chromatography in an 
attempt to establish the optimal conditions for this reaction. This effort led to an increase in yield from $50 \%$ to $70 \%$ of the pure epoxide 4 after vacuum distillation.



Scheme 1. Three-step simultaneous synthesis of trans-syn-trans (1) and trans-anti-trans (2) isomers of DCE18C6. (i) $m$ CPBA, DCM, rt, 12 h, 70\%. (ii) di(ethylene glycol), NaH, $60{ }^{\circ} \mathrm{C}, 42 \mathrm{~h}, 32 \%$. (iii) di(ethylene glycol) ditosylate, 60\% NaH, DMSO, rt, 18 h, 17\% (1), 25\% (2).

The residue consisted of crude bisepoxides $4 a$, in a 57:43 ratio favoring the cis isomer, in accordance with the literature. ${ }^{17,18}$ The slight preference for the cis-isomer can possibly be explained by a hydrogen-bondingeffect between $m C P B A$ and the epoxide oxygen on 4. Next, we evaluated several reaction conditions to construct the half-crown intermediates $\mathbf{5}$ and $\mathbf{6}$, and obtained our best results employing a modified solventfree procedure based on the work of Yamato et al. ${ }^{15}$ Two equivalents of epoxide 4 were reacted with diethylene glycol in the presence of a catalytic amount of sodium hydride at $60^{\circ} \mathrm{C}$. This resulted in a combined $32 \%$ yield for the trans-syn-trans (5) and trans-anti-trans (6) diols after chromatography. Cyclization to the desired dicyclohexeno-18-crown-6 was conducted following a procedure as described by Huber and Dietz. ${ }^{13}$ The diols were transformed into their corresponding alkoxides using stoichiometric quantities of sodium hydride, after which they were allowed to react with di(ethylenegylcol) ditosylate to give the trans-syn-trans (1) and trans-anti-trans (2) isomers of DCE18C6 (1:1 ratio by NMR). To our disappointment, attempts to separate the isomers through crystallization were unsatisfactory, in contrast to what had been reported for the analogous DC18C6 isomers. ${ }^{15}$ Luckily, the products could be separated by chromatography on silica and, in contrast to the literature, ${ }^{15}$ both compounds were obtained in pure form. The meso isomer 1 and racemic isomer 2 were isolated in $17 \%$ and $25 \%$ yields, respectively.

The relative stereochemistry of 1 and $\mathbf{2}$ were determined unequivocally by X-ray crystallography. Suitable crystals of both samples were obtained through slow evaporation of $n$-hexane. The trans-syn-trans- DCE18C6 (1) crystallizes in the triclinic space group P-1 with two half-molecule fragments in the asymmetric unit straddling an inversion center. ${ }^{19}$ The two fragments are nearly superimposable on each other with only slight deviations in the dihedral angles around the ethylene linkages. Both fragments contain an identical trans-syntrans stereochemistry around the cyclohexene moieties. An ORTEP diagram for one of the molecules of transsyn-trans-DCE18C6 (1) is shown on the left in Figure 2. The trans-anti-trans isomer, (2), crystallizes in the orthorhombic space group Pbca with one complete molecule in the asymmetric unit. ${ }^{19}$ The trans-anti-trans isomer's relative stereochemistry is clearly displayed in the ORTEP drawing shown on the right in Figure 2. 


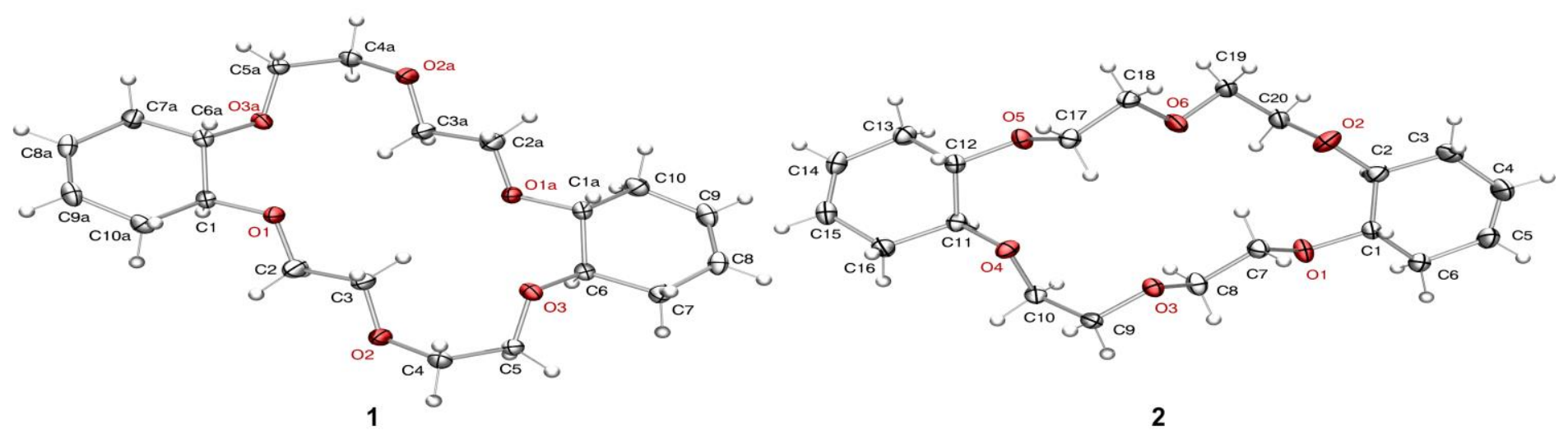

Figure 2. ORTEP diagram of trans-syn-trans DCE18C6 (1) and trans-anti-trans DCE18C6 (2).

\section{Conclusions}

We have developed the first synthesis of two stereoisomers of dicyclohexeno-18-crown-6 in order to provide suitable starting structures for the future preparation of diverse functionalized DC18C6. A convenient 3-step route combined with a chromatographic separation of the final products resulted in the isolation of the pure crown ethers. Future work includes further functionalization to more advanced materials, and optimization of the synthetic protocol. The possible changes of metal complexation by dicyclohexeno-18-crown- 6 compared to the saturated analogues is also of substantial interest.

\section{Experimental Section}

General. Starting reagents were purchased from commercial sources (Sigma Aldrich, TCl, Alfa Aesar) and used without additional purification. All solvents were dried/purified by conventional techniques. The reactions were monitored by TLC on silica gel $(8 \times 2 \mathrm{~cm})$ plates from Analtech Inc. (visualization by UV light and/or staining with $\left.\mathrm{I}_{2}\right)$. Column chromatography was performed on silica gel $\left(40-75 \mu \mathrm{m}\right.$, Sorbent Technologies). ${ }^{1} \mathrm{H}$ NMR and ${ }^{13} \mathrm{C}$ NMR spectra were acquired on JEOL ECA-600 NMR-spectrometer (600 MHz for ${ }^{1} \mathrm{H}$ and $151 \mathrm{MHz}$ for ${ }^{13} \mathrm{C}$ ). High resolution mass spectra (HRMS) were obtained on a JEOL AccuTOF time-of-flight mass spectrometer (Peabody, MA) coupled with an lonsense DART open-air ionization source (Saugus, MA). Crystallographic data were collected at $150 \mathrm{~K}$ using a Bruker Smart Apex II single crystal diffractometer with $\operatorname{MoK}_{\alpha}(\lambda=0.71073 \AA)$ using omega and psi scans. Frames were integrated with the Bruker SAINT software package using a narrow-frame algorithm. Data were corrected for absorption effects using the Multi-Scan method (SADABS). The structures were solved and refined using the Bruker SHELXTL Software Package.

Synthesis of 7-oxa-bicyclo[4.1.0]hept-3-ene (4). To a stirred solution of 1,4-cyclohexadiene $(20.0 \mathrm{~mL}, 205$ $\mathrm{mmol})$ in dichloromethane $(1 \mathrm{~L})$ at $0^{\circ} \mathrm{C}$ was added $m$ CPBA $(55.4 \mathrm{~g}, 238 \mathrm{mmol})$ in a portion-wise fashion. The mixture was subsequently stirred at $0^{\circ} \mathrm{C}$ for $1 \mathrm{~h}$, followed by stirring at $\mathrm{RT}$ for $16 \mathrm{~h}$. Next, $5 \% \mathrm{w} / \mathrm{w} \mathrm{Na}_{2} \mathrm{SO}_{3}$ (aq.) $(400 \mathrm{~mL})$ was added, followed by vigorous stirring for $1 \mathrm{~h}$ at RT. The water layer was extracted with DCM $\left(2 \times 200 \mathrm{~mL}\right.$ ). The combined organic extracts were washed with saturated $\mathrm{NaHCO}_{3}$ (aq.) $(2 \times 250 \mathrm{~mL}$ ) and brine 
(1x100 mL), dried over anhydrous $\mathrm{Na}_{2} \mathrm{SO}_{4}$, and concentrated in vacuo. The residual yellow oil was subjected to vacuum distillation $\left(20 \mathrm{mbar}, 47-49^{\circ} \mathrm{C}\right.$ ), yielding the pure epoxide 4 as a colorless oil $(13.73 \mathrm{~g}, 70 \%) .{ }^{1} \mathrm{H}-\mathrm{NMR}$ $\left(600 \mathrm{MHz}, \mathrm{CDCl}_{3}\right) \delta 5.44(\mathrm{dd}, 2 \mathrm{H}), 3.24-3.25(\mathrm{~m}, 2 \mathrm{H}), 2.58-2.60(\mathrm{~m}, 1 \mathrm{H}), 2.54-2.56(\mathrm{~m}, 1 \mathrm{H}), 2.46-2.47(\mathrm{~m}, 1 \mathrm{H})$, $2.43(\mathrm{~m}, 1 \mathrm{H}) .{ }^{13} \mathrm{C}-\mathrm{NMR}\left(151 \mathrm{MHz}, \mathrm{CDCl}_{3}\right) \delta 121.67,51.15,25.11$. HRMS: calculated for $\mathrm{C}_{6} \mathrm{H}_{8} \mathrm{O}[\mathrm{M}+\mathrm{H}]^{+} \mathrm{m} / \mathrm{z}$ 97.0653; observed $\mathrm{m} / \mathrm{z} 97.0646$.

Synthesis of (1S,6S)-6-(2-(2-(((1R,6R)-6-hydroxycyclohex-3-en-1-yl)oxy)ethoxy)ethoxy) cyclohex-3-enol (5) and (1S,6S)-6-(2-(2-(((1R,6R)-6-hydroxycyclohex-3-en-1-yl)oxy)ethoxy) ethoxy)cyclohex-3-enol (6). Diethylene glycol $(5.58 \mathrm{~g}, 52.0 \mathrm{mmol})$ and $95 \% \mathrm{w} / \mathrm{w}$ sodium hydride $(263 \mathrm{mg}, 10.4 \mathrm{mmol})$ were stirred in an oven-dried vessel under argon atmosphere for $0.5 \mathrm{~h}$ at $60^{\circ} \mathrm{C}$. Next, 7-oxa-bicyclo[4.1.0]hept-3-ene 4 (10.0 g, $104 \mathrm{mmol}$ ) was added to the mixture followed by stirring at $60^{\circ} \mathrm{C}$ for $42 \mathrm{~h}$. After cooling to RT, the mixture was diluted with water $(10 \mathrm{~mL})$ and the $\mathrm{pH}$ was adjusted to $7-8$ using $1.1 \mathrm{M} \mathrm{HCl}$. The aqueous mixture was extracted with DCM $(1 \times 50 \mathrm{~mL}, 2 \times 30 \mathrm{~mL})$. The combined organic extracts were washed with brine $(1 \times 20 \mathrm{~mL})$, dried over anhydrous $\mathrm{Na}_{2} \mathrm{SO}_{4}$, and concentrated in vacuo to yield a dark red oil. The crude product was purified by column chromatography $\left(\mathrm{SiO}_{2}, \mathrm{DCM} / \mathrm{MeOH} 39: 1\right)$ yielding half-crowns 5 and 6 as a yellow oil (4.97 g, 32\%). ${ }^{1} \mathrm{H}-\mathrm{NMR}\left(600 \mathrm{MHz}, \mathrm{CDCl}_{3}\right) \delta$ 5.47-5.54 (m, 4H), $5.09(\mathrm{~s}, 1 \mathrm{H}, \mathrm{OH}), 5.04(\mathrm{~s}, 1 \mathrm{H}, \mathrm{OH}), 3.56-3.90(\mathrm{~m}, 10 \mathrm{H})$, 3.36-3.43 (m, 2H), 2.47-2.52 (m, 4H), 1.97-2.11 (m, 4H). ${ }^{13} \mathrm{C}-\mathrm{NMR}\left(151 \mathrm{MHz}, \mathrm{CDCl}_{3}\right) \delta$ 125.15, 125.12, 124.04, $124.01,81.56,81.14,70.92,70.85,70.61,70.42,68.99,68.49,33.28,31.22,31.06$. HRMS: calculated for $\mathrm{C}_{16} \mathrm{H}_{26} \mathrm{O}_{5}[\mathrm{M}+\mathrm{H}]^{+} \mathrm{m} / \mathrm{z}$ 299.1859; observed $\mathrm{m} / \mathrm{z} 299.1820$.

Synthesis of (4aR,11aS,15aS,22aR)-1,4,4a,6,7,9,10,11a,12,15,15a,17,18,20,21,22a-hexadecahydrodibenzo[b,k][1,4,7,10,13,16]hexaoxacyclooctadecine (1) and (4aR,11aR,15aR,22aR)-

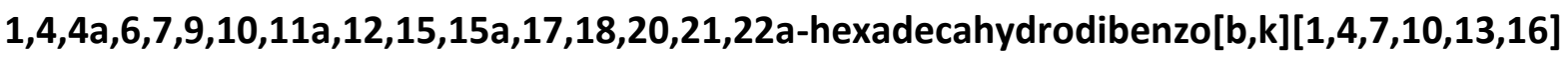

hexaoxacyclooctadecine (2). A mixture of half-crown 5 and 6 (3.50 g, $11.7 \mathrm{mmol})$ in DMSO (14 mL) was added to a stirred suspension of $60 \% \mathrm{w} / \mathrm{w} \mathrm{NaH}$ in mineral oil (1.41 g, $35.2 \mathrm{mmol})$ in DMSO (30 $\mathrm{mL})$ under argon atmosphere. After stirring for $0.5 \mathrm{~h}$, di(ethylene glycol) ditosylate $(5.12 \mathrm{~g}, 11.7 \mathrm{mmol})$ was added to the mixture followed by stirring for $18 \mathrm{~h}$ at RT, after which full consumption of the starting material was observed on TLC. Brine $(36 \mathrm{~mL}$ ) was subsequently added to break down excess $\mathrm{NaH}$, followed by stirring for 5 minutes. Formed solids were filtered off and the solution was extracted with diethyl ether $(5 \times 70 \mathrm{~mL})$ The combined organic extracts were washed with brine $(1 \times 35 \mathrm{~mL})$, dried over anhydrous $\mathrm{Na}_{2} \mathrm{SO}_{4}$, and concentrated in vacuo yielding an orange oil containing isomers 1 and 2 (1:1 ratio by NMR). Column chromatography with gradient elution $\left(\mathrm{SiO}_{2}, \mathrm{DCM} / \mathrm{MeOH} /\right.$ conc. $\mathrm{NH}_{3}$ (aq.) 15:1:.1 $\rightarrow$ 10:1:1) was utilized to yield the pure trans-syn-trans crown ether 1 (white solid, $743 \mathrm{mg}, 17 \%$ ) and pure trans-anti-trans crown ether 2 (white solid, $1.09 \mathrm{~g}, 25 \%$ ). $1:{ }^{1} \mathrm{H}$ NMR $\left(600 \mathrm{MHz}, \mathrm{CDCl}_{3}\right) \delta 5.52(\mathrm{t}, J 1.2 \mathrm{~Hz}, 4 \mathrm{H}), 3.83-3.87(\mathrm{~m}, 4 \mathrm{H}), 3.64-3.76(\mathrm{~m}, 12 \mathrm{H}), 3.57-3.59(\mathrm{~m}, 4 \mathrm{H}), 2.48$ (dd, J 19.5, 3.7 Hz, 4H), 2.06 (ddd, J 15.5, 5.3, 3.2 Hz, 4H). ${ }^{13} \mathrm{C}-\mathrm{NMR}\left(151 \mathrm{MHz}, \mathrm{CDCl}_{3}\right) \delta 124.43,78.59,71.07$, 69.48, 31.34. HRMS: calculated for $\mathrm{C}_{20} \mathrm{H}_{32} \mathrm{O}_{6}[\mathrm{M}+\mathrm{H}]^{+} \mathrm{m} / \mathrm{z}$ 369.2277; observed $\mathrm{m} / z$ 369.2239. 2: ${ }^{1} \mathrm{H}-\mathrm{NMR}$ (600 $\left.\mathrm{MHz}_{,} \mathrm{CDCl}_{3}\right) \delta 5.52(\mathrm{t}, J 1.5 \mathrm{~Hz}, 4 \mathrm{H}), 3.95-3.99(\mathrm{~m}, 4 \mathrm{H}), 3.64-3.73(\mathrm{~m}, 12 \mathrm{H}), 3.52-3.55(\mathrm{~m}, 4 \mathrm{H}), 2.47$ (dd, J 19.5, 3.7 Hz, 4H), 2.07 (ddd, J 15.6, 5.5, 3.2 Hz, 4H). ${ }^{13} \mathrm{C}-\mathrm{NMR}\left(151 \mathrm{MHz}, \mathrm{CDCl}_{3}\right) \delta 124.50,79.26,71.26,70.35,31.66$. HRMS: calculated for $\mathrm{C}_{20} \mathrm{H}_{32} \mathrm{O}_{6}[\mathrm{M}+\mathrm{H}]^{+} \mathrm{m} / \mathrm{z} 369.2277$; observed $\mathrm{m} / \mathrm{z} 369.2249$.

\section{Acknowledgements}

This work was supported by the University of the Pacific's Office of Graduate Studies and College Research Fund. We would also like to acknowledge the NSF Major Research Instrumentation Grant NSF-MRI-0722654. 


\section{References}

1. Pedersen, C. J. J. Am. Chem. Soc. 1967, 89, 7017-7036.

https://doi.org/10.1021/ja01002a035

2. Di Stefano, S.; Biagini, C. Angew. Chemie Int. Ed. 2020.

https://doi.org/10.1002/anie.201912659

3. Gokel, G. W.; Leevy, W. M.; Weber, M. E. Chem. Rev. 2004, 104, 2723-2750.

https://doi.org/10.1021/cr020080k

4. Samoshin, V. V. Rev. J. Chem. 2011, 1, 250-274.

https://doi.org/10.1134/S2079978011020026

5. Samoshin, V. Mini. Rev. Org. Chem. 2005, 2, 225-235.

https://doi.org/10.2174/1570193054368882

6. Han, Y.; Jiang, Y.; Chen, C.-F. Tetrahedron 2015, 71, 503-522.

https://doi.org/10.1016/J.TET.2014.11.006.

7. Xue, M.; Yang, Y.; Chi, X.; Yan, X.; Huang, F. Chem. Rev. 2015, 115, 7398-7501.

https://doi.org/10.1021/cr5005869

8. Zhang, M.; Yan, X.; Huang, F.; Niu, Z.; Gibson, H. W. Acc. Chem. Res. 2014, 47, 1995-2005. https://doi.org/10.1021/ar500046r

9. Kralj, M.; Tušek-Božić, L.; Frkanec, L. ChemMedChem 2008, 3, 1478-1492. https://doi.org/10.1002/cmdc.200800118

10. Stillwell, W.; Stillwell, W. E. An Introduction to Biological Membranes Elsevier, 2016.

11. Albanese, D. Catal. Rev. 2003, 45, 369-395. https://doi.org/10.1081/CR-120025538

12. Izatt, R. M.; Haymore, B. L.; Bradshaw, J. S.; Christensen, J. J. Inorg. Chem. 1975, 14, 3132-3133. https://doi.org/10.1021/ic50154a059

13. Huber, V. J.; Dietz, M. L. Tetrahedron Lett. 2001, 42, 2945-2948.

14. Yamato, K.; Fernandez, F. A.; Vogel, H. F.; Bartsch, R. A.; Dietz, M. L. Tetrahedron Lett. 2002, 43, 52295232.

https://doi.org/10.1016/S0040-4039(02)01040-7

15. Yamato, K.; Bartsch, R. A.; Dietz, M. L.; Rogers, R. D. Tetrahedron Lett. 2002, 43, 2153-2156. https://doi.org/10.1016/S0040-4039(02)00221-6

16. Yamato, K.; Bartsch, R. A.; Broker, G. A.; Rogers, R. D.; Dietz, M. L. Tetrahedron Lett. 2002, 5805-5808. https://doi.org/10.1016/S0040-4039(02)01187-5

17. Clique, B.; Ironmonger, A.; Whittaker, B.; Colley, J.; Titchmarsh, J.; Stockley, P.; Nelson, A. Org. Biomol. Chem. 2005, 3, 2776-2785.

https://doi.org/10.1039/B505865A

18. Kavadias G, Belleau, B. US Patent 4003922; (1977)

19. CCDC 1963312 (1) and CCDC 1963313 (2) contain the supplementary crystallographic data for this paper. These data can be obtained free of charge at www.ccdc.cam.ac.uk/conts/retrieving.html [or from the Cambridge Crystallographic Data Center (CDCC), 12 Union Road, Cambridge CB2 1EZ, UK fax: +44(0) 1223 336 033; e-mail: deposit@ccdc. cam. ac. uk. 